\title{
Clínica, Transmissão e Pesquisa: Uma Direção de Tratamento no Autismo
}

\author{
Ana Beatriz Freire \\ João Cariello de Moraes \\ Universidade Federal do Rio de Janeiro
}

\begin{abstract}
RESUMO
A partir de obras de Freud e Lacan, este artigo propõe interrogar o lugar que ocupa a clínica na Universidade, assim como o lugar que pode ocupar a pesquisa quando associada à clínica e à psicanálise. Interroga-se, também, o lugar da transmissão no campo do saber e do ensino em psicanálise. A partir da pesquisa acadêmica, resultado de um intercâmbio entre Universidade e clínica, mais particularmente a partir do caso de um adolescente autista, pretende-se analisar, de forma crítica, os conceitos originários da psicanálise, tais como transferência, linguagem, objeto e realidade. Visase, ainda, alargar estes conceitos, com a finalidade de modalizar a teoria psicanalítica e buscar circunscrever a especificidade da clínica do autismo e as contribuições possíveis da psicanálise a esta clínica. Em relação ao autismo, este trabalho tem por objetivo pensar sua direção clínica a partir da psicanálise e, especificamente, a partir dos fragmentos clínicos relatados, acompanhar as invenções inéditas encontradas no caso do citado adolescente, para responder a ausência da significação fálica e, consequentemente, da extração do objeto voz.
\end{abstract}

Palavras-chave: transmissão; clínica; autismo; objeto; voz.

\begin{abstract}
Clinic, Transmission and Research: A Course of Treatment in Autism

Based on the works of Freud and Lacan, the present article intends to question the place the clinic occupies at the university, as well as the place that research can occupy when combined with clinic and psychoanalysis. The place of transmission in the field of knowledge and education in psychoanalysis are also questioned. From the academic research, the result of an exchange among universities and the clinic, particularly based on the case of an autistic teenager, we intend to critically examine the concepts originated in psychoanalysis, such as transference, language, object, reality. The aim here is also to extend these concepts in order to modalize the psychoanalytic theory and to circumscribe the specific clinic of autism and the possible contributions of psychoanalysis to this clinic. In relation to autism, the purpose of this study is to think about its clinical direction from psychoanalysis and, specifically, from the reported clinical fragments, to follow the novel inventions found in the case of that teenager in order to respond to the absence of the phallic significance and, consequently, the extraction of the object voice.
\end{abstract}

Keywords: transmission; clinic; autism; object; voice.

$\mathrm{Na}$ aula inaugural de seus seminários, em 1953, Lacan define o pensamento de Freud comparando-o ao mestre budista nos seguintes termos:

O mestre interrompe o silêncio com qualquer coisa, um sarcasmo, um pontapé. É assim que procede, na procura do sentido, um mestre budista, segundo a técnica zen (de zenbudismo). Cabe aos alunos, eles mesmos, procurar a resposta às suas próprias questões. O mestre não ensina ex-cathedra uma ciência já pronta, dá a resposta quando os alunos estão a ponto de encontrá-la. Esta forma de ensino é uma recusa de todo sistema. Descobre um pensamento em movimento... O pensamento de
Freud é o mais perpetuamente aberto à revisão. É um erro reduzi-lo a palavras gastas. (Lacan, 1953/1979, p. 9)

Mais tarde, em 1967, Lacan, na célebre "Proposição de 9 de outubro" (Lacan, 1967/2003), distingue o saber referencial do saber textual. O saber referencial corresponde àquele sobre o qual se aprende, aquele que é estudado nos textos dos mestres. O saber textual diz respeito ao saber inconsciente, que vem a ser construído em uma análise e cuja leitura opera transformações na maneira de apreender o saber referencial, de modo a subjetivá-lo. Aprender a partir da psicanálise implica uma relação com o saber, uma relação que 
coloca como indicador a falha no saber. Freud no início de seu percurso clínico e teórico constatou a falha da transmissão, o não-saber imanente à psicanálise, daquilo mesmo que seus mestres lhe transmitiram:

\begin{abstract}
A idéia [da etiologia sexual] pela qual eu estava me tornando responsável de modo algum se originou em mim. Fora-me comunicada por três pessoas, cujos pontos de vista tinham merecido meu mais profundo respeito - o próprio Breuer, Charcot e Chrobak... Estes três homens me tinham transmitido um conhecimento que, rigorosamente falando, eles próprios não possuíam... essas três opiniões idênticas, que ouvira sem compreender, ficaram adormecidas em minha mente durante anos até que um dia despertaram como um conhecimento aparentemente original. (Freud, 1914/1969a, pp. 22-23)
\end{abstract}

Nesta passagem, encontramos um bom exemplo de transmissão. Transmitir não é, como constata Freud, veicular o dito do que foi enunciado, mas responder a "um conhecimento que, rigorosamente falando", os próprios mestres não possuíam. Sob admiração e transferência por esses três grandes homens, sem mesmo compreender o que diziam, Freud fez do impossível de representar, do que foi dito, uma enunciação, ou melhor, fez do falar, algo da verdade do que se fez ouvir sob a forma do que ele construiu, como mito, como enigma da origem, do que se disse (Jimenez, 1990, p. 35). Adormecida em sua mente durante anos, o não assimilável, o não compreensível, as opiniões do campo do Outro, o opaco do campo do Outro, despertaram sob a forma de uma descoberta original da qual Freud se apropriou, responsabilizando-se por esta, tomando-a como sua enunciação, da posição de sujeito desejante (Diogo, 2008; Jimenez 1990). Constatamos, com esse depoimento de Freud sobre a transmissão, que esta só pode se realizar enquanto tal se, como sujeitos, apropriarmo-nos do que vem do Outro, do saber (S2) e, nesse apropriar-se, tocarmos o que interroga o saber, isto é, o impossível. Esse lugar é o lugar de analisante, daquele que, ao desejar saber sobre o que lhe causa, interroga sobre a verdade, lugar onde o sujeito ao falar, diz o que não sabe e o que não se sabe.

Aprender, a partir da psicanálise, portanto, modifica a concepção de aprendizagem de um saber estabelecido, determinando uma nova relação aos textos, que serão lidos com base na experiência do inconsciente; mais precisamente, interpela a própria ideia de ensinoaprendizagem. Guiado pelo saber textual do inconsciente, o saber referencial não constrói sistemas, nem cria Weltanschauungen (Freud, 1932/1969b), ou seja, não recua e deixa perguntas sem resposta. A advertên- cia de Freud acerca dos analisantes que se interessavam pela literatura psicanalítica evidencia bem a relação não complementar entre as duas formas de saber: ele alerta o analista para a manobra do analisante de poupar-se o sacrifício pessoal de uma análise, substituindo-a pela aquisição de saber referencial, saber estabelecido e que aproximamos do saber exposto, como veremos adiante. Por sua vez, o ensino universitário presta-se, portanto, a velar a falha no saber, aquela que a análise revela. Só no a posteriori cada um poderá testemunhar o que para si teve um efeito formador: tudo aquilo que o autorizou ao ato analítico.

Guiados pela advertência de Freud e Lacan, gostaríamos de interrogar, nesse trabalho, o lugar que ocupa a clínica na Universidade, assim como o lugar que pode ocupar a pesquisa quando associada à clínica e à psicanálise.

O corpo do saber científico e suas aquisições podem ser tomados pelos cientistas, nos seus enunciados, como objetos que não causam o cientista, pois estes não se sentem por estes concernidos. Salientamos a advertência de Lacan quanto ao fato de que, se isto acontecesse - e isso é bem atual -, a relação do sujeito com a ciência tenderia a um tipo de seita, doutrina ou religião (Lacan, 1964/1979, pp. 238-239). É o que acontece quando a ciência faz coincidir o seu ideal com a ciência-ideal, acreditando explicar a contingência por fórmulas necessárias, e reduzindo as invenções e modalidades de circunscrever o gozo a uma natureza hipostasiada por algum postulado dito científico.

Tomemos o exemplo de nossa pesquisa ${ }^{1}$ com autismo na Universidade. Ela começou abordando o campo da psicose em geral em um acordo interinstitucional entre a Universidade (UFRJ) e Instituto Philippe Pinel, e atualmente se desdobrou na pesquisa clínica com o autismo. Propõe um dispositivo inédito de saídas com os adolescentes autistas e psicóticos já crescidos e aponta para o desligamento do serviço infantil no qual fazem tratamento desde crianças. Nossa pesquisa visa os efeitos de um trabalho realizado com adolescentes autistas e psicóticos que participam de um dispositivo de atendimento através do uso de recursos externos ao espaço institucional de tratamento. Esse trabalho implica uma reflexão teórica e clínica da relação da psicose com a possibilidade de laço social.

Tal proposta de trabalho foi criada a partir dos impasses encontrados no serviço infantil que funcionava como uma referência para esses adolescentes que lá se tratavam desde criança. Constatamos que, para as 
crianças e para os pais, o advento da puberdade trouxe novas questões colocadas cotidianamente para a equipe. Confrontados com esta nova realidade, a equipe se viu envolvida com questões levantadas pelas crianças que cresceram. Esses novos adolescentes demandavam nova especificidade no manejo clínico, exigindo que a equipe ressituasse cada caso a partir das discussões entre os clínicos. A complexidade dos cuidados exigidos por esses adolescentes ganhou visibilidade em decorrência da necessidade da criação de outras e novas formas de acompanhamento, distintas daquelas oferecidas exclusivamente para uma clientela infantil.

A relação entre pesquisa e clínica na Universidade nos levou a refletir a difrença, nem sempre evidente, entre discurso universitário e discurso do analista (Freire e Bastos, 2010). Constatamos que a pesquisa na Universidade, longe de reparar os impasses, o impossível próprio da clínica, deve, eticamente, aprender com esses impasses e, a partir deles reposicionar seus conceitos, interrogando-os com base na clínica. No caso da nossa pesquisa (clínica da psicose), podemos nos interrogar o que aprendemos com estes pacientes. Eles nos ensinam, primeiramente, que qualquer saber universitário que se quer totalizante, global e a priori é, no mínimo, vão. Por exemplo, estudando os clássicos da psiquiatria e com base em algumas passagens de Freud, acreditávamos de antemão que não há transferência na psicose. Ora, a clínica com esses pacientes pode até apontar para a tese de que "os psicóticos resistem à transferência", entretanto, eles não deixam de estar na transferência. Nesse caso, ou alargamos o conceito de transferência, tal como o concebíamos para a neurose, ou caímos no extremo oposto: o de condenar a psicose à impossibilidade de tratamento. Lacan, entretanto, seguindo a letra de Freud, escreveu em 1958 "De uma questão preliminar a todo tratamento possível da psicose", em que afirma, como sugere o próprio título do trabalho, que há tratamento possível para a psicose (Lacan, 1958/1998).

Em relação à clínica com o autismo, podemos nos interrogar o que nos ensinam essas crianças e adolescentes. Em linhas gerais, fenomenológica e estruturalmente falando, o autismo se caracteriza por uma resposta extrema frente ao próximo, caracteriza-se por uma extrema solidão e uma grande perturbação (apreendida como invasão) frente ao Outro e ao laço social. Diante desse excesso vindo da alteridade (alteridade que pode ser o próprio corpo pulsional, a linguagem), o autista responde para evitar a enunciação, o dizer do Outro, tomando a alteridade como se ela não existisse. Daí sua insistência e um grande esforço de controlar o que se passa em volta - seja através do mutismo ou da verborragia (enxame de significantes sem que o sujeito se aproprie dele, o que chamamos de "ecolalia") ou manifestações como tapar as orelhas e procurar metodicamente evitar, com seu imobilismo, o imprevisível e o inesperado.

Sobre o autismo Freud não se pronunciou e Lacan, que pouco nos falou dele, legou-nos notas pontuais e preciosas que podemos resumir em dois pontos de direção clínica. Primeiramente, segundo Lacan, os autistas "estão na linguagem", apesar do seu esforço de evitar a enunciação, ou melhor, o lugar de onde o Outro fala, quer dizer, o seu dizer, eles são sobretudo verbosos, isto é, estão no verbo - esta tese é uma resposta às propostas que colocam a criança e sobretudo o autista apenas como objeto do Outro, na dita fase “pré-verbal". É preciso repensar a definição de sujeito para a psicanálise para podermos definir o autista como tal. Apostamos, no entanto, que o autista já é um sujeito mesmo quando por "uma insondável decisão do ser" (Lacan, 1946/1998, p. 179) rechaça a presença do Outro.

Pensamos que, apesar de refutar muitas vezes a fala e o discurso, o autista está, como todo ser falante, no campo da linguagem e, como apostou e propôs Lacan, eles, os autistas, são "personagens, sobretudo, verbosos" (Lacan, 1975/1988, p. 135). Por "verboso", entende-se que eles estão, de forma muito singular, no campo do verbo e da linguagem. Esta forma singular relaciona-se com o fato de a linguagem estar excessivamente, no caso destes sujeitos, associada ao excesso de gozo (Carvalho, 2008). Por estarem no verbo, constatamos, clinicamente, que mesmo que frequentemente não falem, os autistas são passíveis de falar, sobretudo, como observa Maleval (2007), em momentos de devastação. Basta, como nos indica Lacan (1975/1988, p. 135), "não nos ocuparmos demasiadamente deles", nem nos colocarmos no lugar do Outro, o que exacerbaria a posição de objeto no qual toda criança se instaura. Lacan avança na direção de considerar que os autistas articulam muitas coisas e que certamente temos algo a lhes dizer. Cabe aqui verificarmos o que eles articulam.

Daí, a proposta de possibilidade de diálogo através do não sentido, do tratamento do Real e do objeto que eles nos apontam, sem enunciação ou interpretação propriamente ditas, para evitar nos instalarmos no Outro louco e invasor que pode exacerbar, consequentemente, sua posição de não-diálogo com o Outro. "Há um isso fala dele", sem que eles possam se apropriar do que o isso imperativamente o designam como 
sujeitos no lugar de objetos. O diálogo é fazer com que o isso seja menos ameaçador, e para este fim, devemos nos deixar conduzir por eles. Devemos evitar, mais do que nunca, ficar no lugar do saberdevastador, pois onde há saber, há gozo, excesso.

Em segundo lugar, Lacan nos propõe, com já mencionamos, o seguinte saber-fazer na transferência com o autista: se não nos ocuparmos deles, eles podem articular muitas coisas.

Vale a pena reproduzir o diálogo que se estabelece no final da conferência que Lacan pronunciou em Genebra, mais particularmente no debate final deste evento, no diálogo que ele estabelece com o Dr. Cramer, um psiquiatra que trabalhava com autismo e se queixava, não sem razão, que seus pacientes "não conseguem escutar-nos, que permanecem isolados". Quanto a esta dificuldade no saber-fazer com os autistas, Lacan nos afirma: "Mas isto é algo muito diferente. Eles não conseguem escutá-los enquanto você se ocupa deles." E o médico continua: "Mas também é muito difícil escutá-los. Sua linguagem continua sendo um pouco fechada." Em resposta a esta observação, Lacan é enfático: "É precisamente isso o que faz com que não os escutemos. $\mathrm{O}$ fato de que eles não nos escutam. Mas finalmente, sem dúvida há algo para lhes ser dito" (Lacan, 1975/1988, p. 134).

Apostar que os autistas já estão em trabalho é a direção clínica que nos indica Lacan nesse diálogo para evitarmos nos colocar na posição de objeto que satura o gozo do Outro louco. Assim, devemos nos deixar ser conduzidos por eles, ou melhor, utilizando-nos de uma bela expressão de Stevens, na mínima (à peine) presença, "no quase-nada de presença, que o sujeito pode tomar a modalidades diferentes é necessário ser um pouco furado, um pouco incompleto, não no sentido da dimensão de saber", ...mas deixar-se, citando o termo cunhado por Tustin, apprivoiser, ser apreendidos (Stevens, 1988, pp. 25-26). Tratar o Outro, não é, portanto, reparar o Outro, o próximo que errou, consertá-lo, mas nos deixar conduzir pelo autista, acolhendo suas construções, sem nos ocuparmos deles e, consequentemente, tentar ser presente sem sê-lo em demasia - ser presente e um pouco ausente. Uma presença regulada não com os regulamentos, mas no próprio trabalho do sujeito, como constamos no início do tratamento do caso a seguir.

Esta direção teórico-clínico quer se diferenciar das teorias clínicas que têm uma concepção deficitária do autismo: seja uma concepção deficitária do Outro materno (o que se nomeia "maternagem"), uma recuperação do lugar da mãe que supostamente não preen- cheu sua função, como em Margaret Mahler (18971985), que acreditava ser o autismo decorrência de uma incapacidade inata na relação afetiva com o outro; na relação mãe/bebê, ou como Bruno Bettelheim (1903-1900), que privilegiava noções psicológicas do desenvolvimento e postulava o autismo como uma fortaleza vazia das relações "reais com os objetos"; ou mesmo Tustin (1995), que acreditava em uma ruptura traumática como etiologia para o autismo (Chiapetta, 2009).

Além da "maternagem", vale a pena lembrar, na atualidade, as concepções clínicas derivadas do discurso da ciência, que se apoiam na neurociência, buscando através deste saber um fundamento para explicar a suposta natureza deficitária dos comportamentos. Nesta direção de um ideal de ciência, a neurociência acredita, no caso do autista, poder explicar, e mesmo querer controlar ${ }^{2}$, por meio da teoria dos neurônios espelhos, o comportamento destes pacientes, reduzindo, consequentemente, às falhas da rede neurológica, suas invenções e suplências - suplências que, muitas vezes, se prestam às verdadeiras próteses em relação à ausência do falo como órgão extraído (como quarto termo que propiciaria a amarração dos registros, Real, Simbólico e Imaginário). No caso dos autistas, não seria pela "boa" intenção da ciência em detectar a rede de neurônios espelhos que poderemos acreditar suprir o seu dito processo deficitário, reparando-o pelo "bom" uso de próteses neurológicas, como se essas pudessem substituir as construções próprias dos autistas - como veremos em seguida um exemplo de nossa própria pesquisa.

Ao longo desses últimos quatro anos de trabalho com tais adolescentes autistas e psicóticos, foi possível recolher alguns efeitos produzidos no que se refere às suas elaborações/produções, reconhecendo aí o trabalho de um sujeito numa tentativa de constituir-se a partir da construção de laços possíveis e, muitas vezes, inéditos. Ao invés de considerarmos as manifestações próprias ao quadro de autismo como condutas desviantes ou produtos patológicos nos quais são identificadas e classificadas como estereotipias, comportamentos bizarros, agressões e agitações, nos alinhamos com a direção de trabalho que destaca a singularidade do adolescente, com a subsequente extração da lógica própria ao caso.

Passaremos, neste momento, para uma exposição mais detalhada do percurso de trabalho que Danilo vem realizando desde que iniciou sua participação nesse dispositivo de tratamento. Entendemos que mu- 
danças significativas ocorreram em sua maneira de enlaçamento com o outro, efeitos de subjetivação e novos projetos se colocaram para Danilo.

\section{A história de Danilo3}

Danilo é filho de estrangeira com pai brasileiro. Sua mãe deixou a terra natal para casar-se e se sentia desamparada. Várias tinham sido as tentativas de engravidar, mas, do nascimento de Danilo, sua mãe apenas guarda a lembrança de que ele "passou da hora de nascer". Era um bebê que quase não chorava.

Aos três anos de idade, Danilo deu sinais de que algo não ia bem. Nada falava e mostrava-se agressivo. Sua mãe engravidou do segundo filho e retornou ao país natal. Sentiu-se acolhida pela família, mas percebeu o afastamento de Danilo. Nesse momento, Danilo pronunciou as primeiras palavras, interrompidas por ocasião do desmame. O quadro clínico se agravou quando foi afastado da mãe, que passou a dedicar-se ao filho mais novo, hospitalizado para uma intervenção cirúrgica. No país natal de sua mãe, Danilo recebeu o diagnóstico de autismo. No Brasil, desde 1998 está em tratamento no serviço infantil no Instituto Philippe Pinel.

\section{0 encontro}

Danilo estava com 20 anos quando aceitou participar da nossa proposta clínica ${ }^{4}$. Seu primeiro encontro com outros adolescentes lhe causou estranheza. Recusou-se a sair para o passeio programado para aquele dia e colocou como condição para se incluir no trabalho ser acompanhado individualmente. Com esta condição colocada, Danilo nos indica sua forma particular de dar tratamento ao Outro louco, ao gozo excessivo, ao próximo inassimilável, que o ameaçava. Foi desta forma que Danilo, inicialmente, foi recebido para atendimento individual.

\section{Primeiro tempo: 0 adolescente e sua invenção em direção ao laço social: a voz de Donald}

Danilo nada falava, comunicava-se apenas por gestos ou acenando com a cabeça. Os clínicos propuseram algumas atividades pelas quais não se interessou. Afastou-se por um pequeno período e, quando retornou, aceitou estar com outros adolescentes, passando a falar sobre futebol e sobre seu time, com o uso de uma voz metalizada, que a mãe nomeia de "voz de Donald". Essa voz de Donald, da qual ele se apropriava como uma maneira defensiva na relação com a família, intensificou-se no tratamento e, a partir desta,
Danilo cavou um lugar e um diálogo com o clínico. Ainda nos perguntamos se a "voz de Donald" já era utilizada por ele ou se foi apropriada como instrumento de diálogo com o clínico. E se isso não poderia ser considerado, pelo laço que estabelece com o Outro, uma "lalangue de transferência"? Em todo caso, por meio desta modalização de voz, ele conseguiu estabelecer um diálogo de transferência com João, o clínico que o atendia, o que lhe propiciou um laço possível com os outros que o cercavam.

Danilo, com a produção da voz do Pato Donald, mostra sinais de diálogo. Às vezes, entretanto, a "maquinização" da voz é tamanha que fica difícil conversar. Foi, a partir do não sentido, do não compreensível, que o clínico propôs o uso da escrita como um recurso, o que Danilo aceitou. Por meio da escrita, conseguimos, em alguns momentos, um diálogo com Danilo: troca de palavras, olhares e estabelecer negociações. Às vezes é possível perceber que ele se aproxima do ouvido do clínico e, falando baixinho, parece deixar "afrouxar" a voz do Donald. Fica evidenciado, neste momento, a tentativa por parte de Danilo de flexibilizar sua estratégia defensiva, "sua recusa de apelo ao Outro, assim como sua recusa em engajar a voz na fala" (Maleval, 2007, p. 72). Pensamos que a partir desse momento, Danilo estaria tentando modalizar e, senão ceder, "afrouxar" o objeto do gozo vocal.

\section{Segundo tempo: ainda em direção ao diálogo com o outro: "eu não sei dizer, nada por dizer, então eu escuto..."}

Na tentativa de a mãe formar parceria com o clínico frente à decisão de Danilo em não continuar frequentando a escola especial, este, percebendo a "cumplicidade" que estava se estabelecendo entre eles, faz gestos obscenos como "dar bananas". Indiretamente interrogado pelo clínico sobre a questão da escola especial, ele prontamente responde: "Eles são mais doentes do que eu!" A mãe, com surpresa e espanto, comenta: "Ele soltou, soltou!". Esse acusar recepção do que "escapou" ao filho, do que ele "soltou" produziu um efeito de subjetivação frente à ameaça e aos significantes avassaladores que vêm do Outro.

Danilo mostra sinais de diálogo. Pela primeira vez fala dos planos para o final do ano sem usar a voz do Donald e à pergunta do clínico ele responde: "Outubro, novembro e dezembro". O clínico limita-se a acusar recepção e sinaliza que, naquele momento, Danilo se fez entender e mostra alegria. Este, com a voz "falhando", acrescenta que em dezembro tem o Natal e que irá ganhar presente. Em seguida, chega 
falando normalmente. Diante da proposta de agendar uns passeios com o clínico, o jovem paciente destaca uma data específica no calendário e fala que não sabe qual será o dia da semana que lhe corresponderia. Danilo dá um tapinha na cabeça e diz: "anda cabeça". O clínico, então, lhe diz que não há problema em se confundir, que todo mundo às vezes se confunde e sublinha o limite daquilo que nos escapa.

Nessa intervenção, o clínico notificando a falha, aponta como direção de tratamento não a reparação, mas o impossível da relação própria que nos escapa, entre ele e o objeto que se modula. Acusando recepção, João fez valer essa tentativa de circunscrever "o próximo" como "a iminência intolerável do gozo" (Lacan, 1968-1969/2008, p. 225), relevando essa invenção à categoria de modulação de gozo, o que permitiu um diálogo deste adolescente com os outros. Para que Danilo suportasse o outro como parceiro de suas invenções, foi preciso que o próximo intolerável, na impossibilidade de ser totalmente limpo e negativizado na sua plenitude de gozo (idem), fosse ao menos modalizado no seu gozo vocal. A partir dessa invenção, Danilo tenta circunscrever o inassimilável do próximo, encarnado na mãe estrangeira cuja profissão é ensinar sua língua materna.

$\mathrm{Na}$ impossibilidade de extração do objeto, esse sujeito tentou se inscrever no discurso, fazendo desta voz inventada, função de órgão, como substituto, modalização do objeto "voz não extraído". Apostamos que a voz de Donald é uma modalização do objeto voz que pode trazer, no tratamento, a dimensão de invenção, forjada por este jovem, enlaçando-o, de forma inédita e própria, ao social.

Vale lembrar que por consequência da não extração do objeto do campo da realidade devido à rejeição do Nome-do-Pai e, concomitantemente, da não referência à significação fálica, a psicose, como assinala Lacan, "leva o objeto $a$ no bolso" (Lacan, 1967/2003), não cedendo, em um primeiro momento, o gozo do objeto ao Outro. Nesse sentido, como assinala Maleval (2007, p. 73), a cessão do objeto do gozo vocal ao gozo do Outro é insuportável para o autista, pois o gozo vocal aponta para a presença da enunciação e para o imperativo do apelo atrelado à questão do que o outro quer de mim. Essa ameaça, no entanto, pode ser manejada se o clínico que o acompanha deixar-se conduzir pelas atividades, iniciativas do paciente, tornando o imperativo menos ameaçador, e transformando o que era apenas ação defensiva em laço e invenção. No caso desse jovem paciente, a partir da docilidade do clínico que regulou sua presença enun- ciativa, foi possível para ele tomar a palavra sem que lhe despertasse horror e devastação.

No fim desse encontro, ele canta: "Eu não sei dizer, nada por dizer, então eu escuto" (alusão à música cantada por Ney Matogrosso, enquanto no grupo Secos e Molhados).

\section{Terceiro tempo: novos projetos}

Constatamos que, a partir do não saber, os fios e restos que são notificados no tratamento, esse jovem consegue, a cada vez, circunscrever a alteridade inassimilável, o gozo imperativo que o avassalava, o que o leva, consequentemente, a poder escutar e, sobretudo, planejar de forma assintótica novos projetos. A partir de então, Danilo menciona sua aspiração de casar com uma mulher, da mesma nacionalidade que a mãe; assinala o seu interesse por televisão e por CDs; e, também, a vontade de trabalhar na tevê, no Projac ${ }^{5}$. No lugar de ir à escola, ele projeta planos e um lugar próprio no Projac.

Danilo tem realizado um interessante trabalho com as trilhas sonoras das novelas, gosta bastante de cantar as canções destas trilhas. Da voz baixinha à voz de Donald e, posteriormente, em direção à voz cantada, esse jovem construiu um lugar para si no e com o campo do Outro.

\section{REFERÊNCIAS}

Bettelheim, B. (1967). A fortaleza vazia (M. E. H. Cavalheiro, Trad.). São Paulo: Martins Fontes.

Carvalho, E. (2008). Sobre a função na direção do tratamento analítico do autismo. Tese de doutorado não-publicada, Universidade Federal do Rio de Janeiro.

Chiapetta, F. (2009). Autismo e psicanálise: O lugar possível do analista na direção do tratemento. Curitiba: Juruá.

Diogo, D. (2008). A construção do laço social na psicose. Tese de doutorado não-publicada, Universidade Federal do Rio de Janeiro.

Freud, S. (1969a). História do movimento psicanalítico (J. Salomão, Trad.). Em J. Salomão (Org.), Edição standard brasileira das obras completas de Sigmund Freud (Vol. 14, pp. 16-88). Rio de Janeiro: Imago. (Original publicado em 1914)

Freud, S. (1969b). Conferência XXXV: A questão de uma Weltanschauung (J. Salomão, Trad.). Em J. Salomão (Org.), Edição standard brasileira das obras completas de Sigmund Freud (Vol. 22, pp. 193-220). Rio de Janeiro: Imago. (Original publicado em 1932)

Freire, A. B., \& Álvares, K. (2009). Inventando possíveis laços com adolescentes autistas e psicóticos: Um caso clínico. Em F. C. Moura (Org.), Psicanálise e laço social (pp. 82-100). Rio de Janeiro: 7 Letras.

Freire, A. B., \& Bastos, A. (2010) Psicanálise na universidade: Saber, verdade e discursos. Estudos Lacanianos, 3. Retirado 
em 10 de fevereiro de 2011, de http://pepsic.bvsalud.org/scielo. php?script=sci_arttext\&pid=S1983-07692010000100007\&lng $=$ pt\&nrm $=$ iso

Jimenez, S. (1990). Como ensinar psicanálise. Cadernos de Psicanálise, 11, 33-39.

Lacan, J. (1979). O seminário, livro XI: Os quatro conceitos fundamentais (M. D. Magno, Trad.). Rio de Janeiro: Zahar. (Original publicado em 1964)

Lacan, J. (1986). O seminário, livro I: Os escritos técnicos de Freud (B. Millan, Trad.). Rio de Janeiro: Zahar. (Original publicado em 1953-54)

Lacan, J. (1988). Conferencia en Ginebra sobre el sintoma (M. Cifali, Trad.). Em J. Lacan, Intervenciones y textos (p. 115144). Buenos Aires: Manatial. (Original publicado em 1975)

Lacan, J. (1998). Formulações sobre a causalidade psíquica (A. Chelini, Trad.). Em J. Lacan (Org.), Escritos (pp. 152-196). Rio de Janeiro: Zahar. (Original publicado em 1946)

Lacan, J. (1998) De uma questão preliminar a todo tratamento possível da psicose (V. Ribeiro, Trad.). Em J. Lacan (Org.),
Escritos (pp. 537-590). Rio de Janeiro: Zahar. (Original publicado em 1958)

Lacan, J. (2003). Proposição de 9 de outubro de 1967 sobre o psicanalista da escola (V. Ribeiro, Trad.). Em J. Lacan, Outros escritos (pp. 248-264). Rio de Janeiro: Zahar. (Original publicado em 1967)

Lacan, J. (2008). O seminário, livro XVI: De um Outro ao outro (V. Ribeiro, Trad.). Rio de Janeiro: Zahar. (Original publicado em 1968-1969)

Maleval, J. C. (2007). "Sobretudo verbosos", os autistas. Latusa, $12,69-91$.

Laurent, E. (no prelo). A leitura cerebral e seus erros. Fórum de Ciência e Cultura da UFRJ.

Stevens, A. (1988). Aux limites du lien social, les autismes. Les Feuillets $d u$ Courtil: Publication du Champ Freudien en Belgique, 29, 9-28.

Tustin, F. (1995). A perpetuação de um erro. Letra Freudiana, 2, 53-79.

\section{Notas:}

1 A referida pesquisa, coordenada por Ana Beatriz Freire e intitulada "Dispositivo clínico ampliado: Criança e adolescente psicóticos em direção ao laço social e à inclusão escolar", originou-se do Projeto Integrado de Pesquisa desenvolvido no Programa de Pósgraduação em Teoria Psicanalítica do Instituto de Psicologia da UFRJ (PPTP-UFRJ), em convênio com o Instituto Municipal Philippe Pinel, a saber, o projeto "Princípios da Psicanálise no atendimento ao adolescente no laço social". A esse eixo central de pesquisa associa-se um segundo projeto intitulado "Inclusão escolar de crianças e adolescentes autistas e psicóticas: Estudo e acompanhamento de casos", executado pela doutoranda do PPTP-UFRJ Jeanne Marie Costa Ribeiro, sob orientação de Angélica Bastos Grimberg. Neste projeto, cria-se um dispositivo clínico que visa uma possível inserção social utilizando, para esse fim, recursos da comunidade e inclusão escolar; esforço que coaduna às avaliações da OMS (2001) que indicam que o uso dos recursos da família e da comunidade, associados ao tratamento convencional, pode propiciar laços inéditos com o outro. Atualmente, ramificou-se desta pesquisa um trabalho individual com os pais supervisionado por Elisa Carvalho, doutoranda do PPGTP e membro da pesquisa.

2 A hipótese dos neurônios-espelho consiste em supor a existência de neurônios especializados no movimento do outro - isto é, os neurologistas acreditam que podemos reconhecer, imaginariamente, o outro graças ao encadeamento neuronal fundamental destes neurônios. Neste sentido, a rede destes neurônios estaria deficiente no caso dos autistas, já que estes não se reconhecem no Outro e não podem se identificar ao sentimento do campo do outro. Como prevenção, as pesquisas da neurociência têm como objetivo buscar reconhecer e controlar esses neurônios-espelhos com a finalidade de intervir em seu déficit, que segundo essas investigações, caracterizariam, por exemplo, os autistas (Laurent, no prelo).

3 Caso publicado em coletânea do Programa de Pós-Graduação em Teoria Psicanalítica do Instituto de Psicologia da UFRJ (Freire \& Álvares, 2009).

4 O clínico que acompanhou o caso durante esses anos de trabalho dentro desse dispositivo clínico aqui descrito foi João Cariello de Moraes, coautor deste artigo.

5 O Projac, também conhecido como Central Globo de Produção, é considerado o maior núcleo televisivo da América Latina. É o centro de produção da Rede Globo, localizado em Jacarepaguá, no Rio de Janeiro.

\section{Sobre os autores:}

Ana Beatriz Freire - Psicanalista, Mestre e Doutora em Psicologia (Psicologia Clínica) pela Pontifícia Universidade Católica do Rio de Janeiro, pós-doutorado no Departamento de Psicanálise da Universidade de Paris VIII. Professora do Programa de Pós-Graduação em Teoria Psicanalítica do Instituto de Psicologia da Universidade Federal do Rio de Janeiro. Pesquisadora do CNPq. Correspondente da Escola Brasileira de Psicanálise e membro do ICP.

João Cariello de Moraes - Psicólogo pela Universidade Federal do Rio de Janeiro (UFRJ) e Universidade de Salamanca (Espanha). Em formação pela Escola Brasleira de Psicanálise (EBP-ICP). Pesquisador da Fiocruz e apoiador da "Estratégia Brasileirinhas e Brasileirinhos Saudáveis", do Ministério da Saúde.

Endereço eletrônico: freireanab@ hotmail.com 